\title{
Editorial: On Insect Molting and Metamorphosis ${ }^{1}$
}

\author{
Jorge A. Santiago-Blay, reporter ${ }^{2}$
}

The preceding paper, authored by Dr. Karel Sláma (Institute of Entomology, Czech Academy of Sciences, Czech Republic), proposes alternative hypotheses to explain molting and metamorphosis in the most hyperdiverse lineage of all, the insects. This, like some other papers authored by Sláma, elicits a diversity of reactions from his colleagues in insect endocrinology and entomology. Two reviewers have requested me to print their remarks, anonymously, and I have agreed to their request and herein serve as a self-appointed rapporteur.

"In the above paper, writing in a characteristically robust way, Dr. Karel Sláma challenges the well-established consensus view of insect developmental endocrinology. His paper includes a brief resume of that model, but as he himself points out, the main thrust of his paper is to review those aspects of insect molting that are hard to reconcile with the widely accepted paradigm.

While he acknowledges that contrasting perspectives exist, Dr. Sláma's article pays most attention to his own ideas. It should be recognised that many of Dr. Sláma's opinions on this matter are not supported by others working in the field. They would argue that the current, widely accepted scientific paradigm is well supported by literally thousands of research papers. They would say that findings that do not fit the basic model are few and can mostly be accommodated by slight refinements.

Conscious that scientific paradigms can never be above criticism, that major advances in understanding occur when such paradigms are overturned, and that the author has a right to his scientific opinion, we nevertheless support Dr Sláma's right to a hearing for his unconventional views. Moreover, we believe that a generally accepted paradigm can only be strengthened by accommodating new evidence that at first appears problematic.

In our view, Dr Sláma's article amounts to a challenge to the insect endocrinology research community to answer several questions:

1. What is the role of the brain in controlling molting? The standard model of molting control considers that the brain acts to initiate molting only by

\footnotetext{
${ }^{1}$ Quoted editorial comments submitted on October 20, 2015. Accepted on October 22, 2015. Last revisions received on October 24, 2015.

${ }^{2} 217$ Wynwood Road, York, Pennsylvania, USA 17402. E-mail: blayjorge@gmail.com
}

DOI: 10.9784/LEB3(3)Santiago-Blay.01

Electronically available on October 31, 2015. Mailed on October 27, 2015. 
stimulating ecdysteroid synthesis. Dr. Sláma suggests that, contrary to the standard model, the brain may act directly on peripheral tissues to trigger molting.

2. Are edcysteroids the insect molting hormones as long established? In the standard model, ecdysone and its analogues are hormones that act to trigger the developmental events of the integument that are usually called molting. Dr. Sláma suggests that, on the contrary, ecdysteroids do not actually initiate molting, but are merely an integrating component of the molting response itself. $\mathrm{He}$ also suggests that ecdysteroids are not true hormones because in at least some cases they are not secreted by centrally located endocrine tissues (the prothoracic glands), but by other tissues, which in some cases are not well identified.

3. What is the role in molting and metamorphosis of the prothoracic glands? Are these glands the sole source of ecdysteroids, and do they also secrete other endocrine agents that also participate in molting control? Dr. Sláma specifically suggests that a peptide hormone secreted by the prothoracic glands plays an important role in molting control.

4. Are JH-I and other related isoprenoids the true insect juvenile hormones secreted by the corpus allatum? In this paper, Dr. Sláma asserts that this is not the case, and the true $\mathrm{JH}$ is likely to be a peptide.

We do not wish to imply, by the way, that Dr. Sláma is right when he asserts that any or all of these questions are not well addressed in the standard model of molting control. In at least some cases, we believe that the necessary evidence to refute Dr. Sláma's interpretation of the experimental evidence is already present in the published literature. In other cases, the exceptions may indeed be unexplained by the current model. But it needs to be borne in mind that biology is replete with special cases; the insects are both evolutionary ancient and highly diverse, and that divergence from the norm in one or more particular insect species does not prove that the standard model is wrong for all the other species. Moreover, it is already known that the endocrine systems of insects do not operate in the same way throughout their lives but undergo significant changes during metamorphosis."

As a remark of potential interest, in October 1915, approximately one hundred years ago, another Czech, Franz Kafka, published one of his most influential works, Die Verwandlung (The Metamorphosis). http://www.agenciasinc.es/Multimedia/Ilustraciones/El-insecto-mas-famoso-dela-literatura-cumple-un-siglo 